\title{
New Formulation with Marine Algae from Black Sea
}

\author{
Emin Cadar \\ Umf "Carol Davila" Bucharest, Faculty of Pharmacy, \\ Traian Vuia, Bucharest, Romania \\ Emilia Mihaela Cadar \\ The School No.30 "Gheorghe Titeica", Constanta, Romania \\ Cristina-Luiza Erimia \\ "Ovidius" University of Constanta, Faculty of Pharmacy, \\ Constanta, Romania \\ Aneta Tomescu \\ "Ovidius" University of Constanta, Faculty of Medicine, \\ Constanta, Romania
}

\begin{abstract}
Seaweed is a natural treasure that can be intensely evaluated for therapeutic purposes. During the past years, it became obvious that the ecosystem presents a marine algae excedent, which should be utilized in one way or another. Marine algae have been intensely studied. The superior exploitation of the marine biomass represents a highly important resource for the pharmaceutical industry, supplying raw material for the extraction of bioactive substances (vitamins, sterols, and aminoacids) and various other substances, the purity of which is strongly connected to the state of the marine ecosystem. In present work the extracts from marine algae are incorporated in type I non-denatured fibrillar collagen matrixes for obtain new pharmaceutical product. In order to obtain therapeutic effects at nanostructure level, it is important to know the rheological characteristics of the relevant mixtures of collagen gels and extracts from marine algae selected for use. In this survey we have studied mixtures made of non-denatured fibrillar collagen hydro-gels where different concentrations of marine algae have been incorporated.
\end{abstract}

Keywords: marine biomass, fibrillar collagen, marine algae, seaweed, bioactive substances 


\section{Introduction}

The first data regarding the use of algae dates back to the year 2500 B.C, while in China they are recorded in literature as early as the $8-6^{\text {th }}$ centuries B.C. In Japan, the product Kombu, which is prepared from Laminaria (angusta, japonica, religiosa) and Alaria species, is consumed. However, only beginning with the 1670s have they been grown a large-scale. Antique Greeks used algae as a remedy against intestinal worms [1]. In Western countries, algae are not yet accepted as normal daily nutrient, maybe due to their less than appealing aspect and insufficient digestion ability. Nonetheless, in various parts of Europe, algae were used as a food product.

Alongside the Romanian coast, from a qualitative point of view, in the year 1935, the number of macrophytes was 77. Between 1970 and1980, only 68 species were recorded. According to other estimates, at the end of the 1990s, only 38 species of Clorophytes were recorded. These observations outline the significant qualitative decline of the Romanian shore macrophytobenthos. During the last seven decades, the progressive diminishing of the macroalgae flora has intensified, with severe consequences on the entire coastal ecosystem. In 199, only the southern part of the Romanian shore exhibited a more specific diversity. Vegetation impoverishment, especially after 1970 , is due to natural and anthropologic causes which have deteriorated the marine system (severe frosting, argyle sedimentation on bottom rocks, a decrease in light penetration in the water column due to suspensions, increase in eutrophication) [1][2].

Along with the increase in eutrophication, significant qualitative changes were noted in the structure and function of the macrophytobenthos, starting with the oldest records up to the end of the year 2000. Due to important amounts of suspended particles and plankton, the transparency of the sea water registered significant changes, with a considerable decrease. The position of the compensation point changed in such a way that bottom plants that were growing at depths over 7-8 metres became shadowed. This has contributed to the decline of macrophytes, despite large quantities of nutrients. Consequently, due to a large variability of ecologic factors, these changes of the ecosystem and community structure has lead to certain phytocenses being replaced by others. The consequene has been a change in seasonal and multiannual dynamics of the algae communities. The interaction between various anthropologic factors on vegetation has lead to various results, from a structural simplification to complete disappearance. Following hydrotechnics construction work, the algae bed was covered with mud and/or sand. Under these circumstances, Cystoseira Ag. species were replaced by Cladophora and Ceramium, these macrophytes being usually seen in shore areas, at depths lower than 3 metres, were eutrophication tolerant species have emerged such as Enteromorpha intestinalis and Cladophora vagabunda [1], [3].

The most frequent species belong to the Enteromorpha and Ceramium genus, but also Cladophora, Porphyra Ag. and Callithamnion Lyngb. Usually, Enteromorpha species are 
mixed in this green algae belt with Cladophora species, and, in particular, Cl. sericea (Huds), Kutz and, sometimes, Cl. albida (Huds) Kutz. and Cl. laetevirens (Dillw.) Kutz [4]. Although in a reduced number (qualitatively), the remaining species have developed considerable productivities on the available rocky substrates; the common algae populations, represented primarily by Enteromorpha and Ceramium species cover $80 \%$ of this substrate.

During the past years, it became obvious that the ecosystem presents a marine algae excedent. The phytochemical studies on the algae (inferior marine plants belonging to the Thallophyta systemic category) presents the possibility of their usage as raw material, due to the high context in poli-sugars, such as [5], [6]:

- alginates (the alginic acid and its metallic salts, organic bases or their derivates), characteristic for the brown algae,

- the agar-agar (co-polymer of D-galactoze with 3,6-anhydro-L-galactoze, partially esterified with sulphuric acid characteristic for the red algae,

- various L-type monozes-galactoze, 3,6-anhydro-D-galactoze, L-frucoze, Dmaluronic and L-guluronic acids, cellulose, chracacteristic for the green algae.

- In addition, aminoacids (especially in green alage, such as Ulva lactuca) - among which the 8 that are essential for the human organism, and that impossible to be synthesized: izoleucine, leucine, lizine, metionine, fenil-alanine, treonine, triptofan, valine - are present in the algae.

Furthermore, the extraction of agar-agar from red algae Phyllophora nervosa, Ceramium rubrum, C. elegans, Callithamnion corymbosum, Polysiphonia violaceea) can provide vegetal geloze [3]. For the Romanian littoral area, the marine materials are easily accessible [4]. In literature on the matter, attempts of obtaining pharmaceutical products from the Romanian shore marine algae as alcoholic extracts incorporated in collagen hydrogels have been recorded [2]. The active principles identified in the Black Sea algae have drawn researchers' attention for their use in obtaining new pharmaceutical products [5][7][8].

The present study outlines the obtaining of new pharmaceutical formulations using marine algae, collagen, and hyaluronic acid. Each of these components has their own individual properties. The main goal is obtaining time-stable products with beneficial effects on various skin disorders.

\section{Materials and Methods}

The materials used are represented by green marine algae from the Enteromorpha intestinalis and Cladophora vagabunda species. Enteromorpha (Enteromorpha intestinalis),one of the mmost common green seaweeds to be found in shallow rockpools which copes with high temperatures and changes in salinity [3], [4]. From macroscopic and microscopic observations, the following descriptions can be made [3]: 
Table 1. The macroscopic examination of the analysed marine algae [3], [5]

\begin{tabular}{|c|c|}
\hline Cladophora Vagabunda & Enteromorpha intestinalis \\
\hline $\begin{array}{l}\text { QMultiannual alga, } 10-15 \mathrm{~cm} \text { tall; } \\
\text { Strong discoidal rhizoid; } \\
\text { Filamental tale with ramifications, } \\
\text { Bushy aspect; } \\
\text { Filaments formed of long continuous cells; } \\
\text { Terminal ramifications in groups of } 4-6 \text {, } \\
\text { bent as a sickle. }\end{array}$ & $\begin{array}{l}\text { green multimulticellular alga, with a } \\
\text { single-cell layer tale } \\
\text { height - from a few } \mathrm{cm} \text { to } 1 \mathrm{~m} \text {, width - from } \\
1 \mathrm{~mm} \text { to } 10 \mathrm{~cm} \text {; } \\
\text { disk-like rhizoid; } \\
\text { short, cylindric cauloid; } \\
\text { intestine-like filoide. }\end{array}$ \\
\hline
\end{tabular}

Table 2. The microscopic examination of the analyzed algae [3]

\begin{tabular}{|l|l|}
\hline Cladophora Vagabunda & Enteromorpha intestinalis \\
\hline Multiannual alga, $10-15 \mathrm{~cm}$ tall; & green multimulticellular alga, with a single- \\
Strong discoidal rhizoid; & cell layer tale \\
Filamental tale with ramifications, & height - from a few cm to 1m, width - from 1 \\
Bushy aspect; & mm to $10 \mathrm{~cm} ;$ \\
Filaments formed of long continuous cells; & disk-like rhizoid; \\
Terminal ramifications in groups of 4-6, & short, cylindric cauloid; \\
bent as a sickle. & intestine-like filoide. \\
\hline
\end{tabular}

The algae used were in powder form.

Type I fibrillar collagen

Collagen hydrolysate is obtained from bovine skin. Collagen, under all its characteristic forms, presents as a polymer with triple helix structure, which individualizes through intense hydrophilia, variable ionic characters and diverse functionality (Fig. 3).

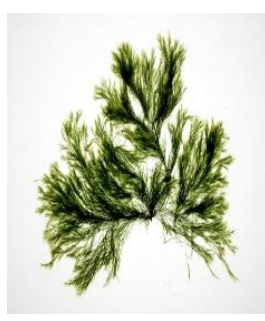

Fig. 1 Cladophora Vagabunda
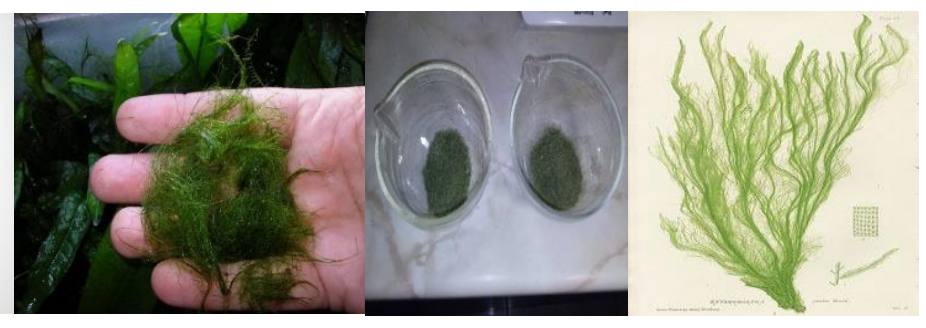

Fig. 2 Enteromorpha intestinalis

It can be involved in a wide number of interaction systems with other micro- or macromolecular components. Currently, in vertebrates, at least 27 different types of 
collagen are known, which exhibit a remarkable diversity in what regards molecular and supramolecular organisation, tissue distribution and function.
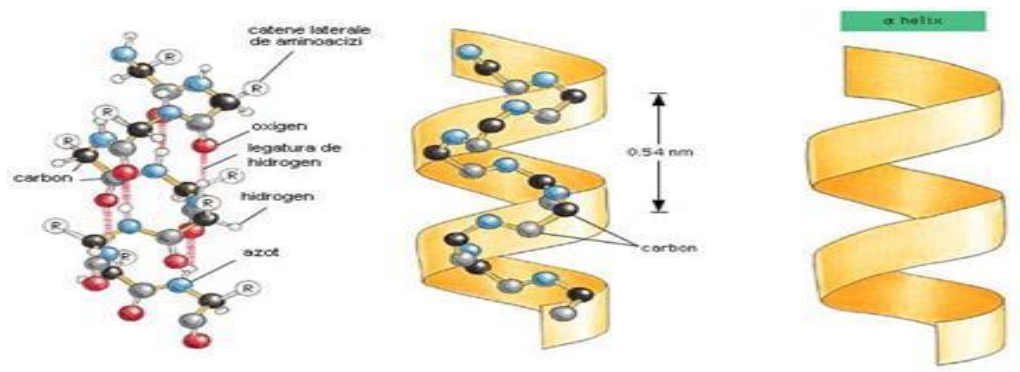

Fig 3 Collagen triple helix function

From this material, mixtures with varying collagen and Black Sea green algae composition were made (Fig. 4).

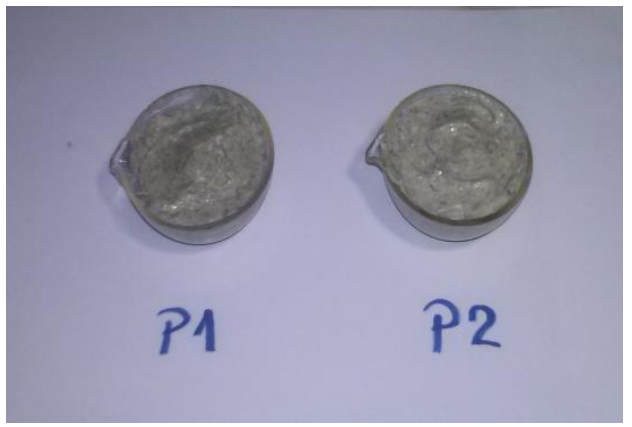

Fig 4 Products obtained from a collagen and different percentages of green algae

In order to select the product with the best stability, rheological studies were performed. In stability tests, the rotational viscometer Reovscostar R was used. Viscosity was measured at various rotation speed for the collagen products containing different percentages of green algae. Reading times were identical every 10 seconds, for 10 minutes.

\section{Results and Discussions}

The formulations were obtained from collagen gels and green algae. Rheological studies were performed through viscosity measurements at varying rotation speeds. Thus, we established the $\mathrm{D}\left(\mathrm{s}^{-1}\right)$ shear rate gradient, for which the $\eta$ (cPoise) viscosity was obtained. From experimental data analyses, rheological parameters were obtained for each formulation:

- For the P1 formulation with $4.76 \%$ green algae in collagen hydrolysate, the values from Table 1 were obtained. 
Table 1. Rheological parameters for P1

\begin{tabular}{|l|l|l|}
\hline Viscosity $\eta(\mathrm{cP})$ & Shear rate $\mathrm{D}\left(\mathrm{sec}^{-1}\right)$ & Shear stress $\tau(\mathrm{Pa})$ \\
\hline Interval between & Interval between & Interval between \\
$19700 \mathrm{cP}$ and $3800 \mathrm{cP}$, & $4,8\left(\mathrm{sec}^{-1}\right)$ and $68\left(\mathrm{sec}^{-1}\right)$ & $80,37 \mathrm{~Pa}$ and $258,4 \mathrm{~Pa}$. \\
\hline
\end{tabular}

- For the P2 formulation with 7\% green algae in collagen hydrolysate, the values from Table 2 were obtained.

Tabelul 2 parametrii reologici pentru P2

\begin{tabular}{|l|l|l|}
\hline Viscosity $\eta(\mathrm{cP})$ & Shear rate $\mathrm{D}\left(\mathrm{sec}^{-1}\right)$ & Shear stress $\tau(\mathrm{Pa})$ \\
\hline Interval between & Interval between & Interval between \\
$21323 \mathrm{cP}$ and $8000 \mathrm{cP}$, & $6,8\left(\mathrm{sec}^{-1}\right)$ and $34\left(\mathrm{sec}^{-1}\right)$ & $145 \mathrm{~Pa}$ and $268,6 \mathrm{~Pa}$. \\
\hline
\end{tabular}

Measurements were made both at rotation speed increase and decrease. Rotation speed was between $12 \mathrm{rpm}$ and $200 \mathrm{rpm}$ for formulation P1 and between $12 \mathrm{rpm}$ and $100 \mathrm{rpm}$ for formulation P2. For rheological analyses, graphics were used so as to follow rheograms (Fig. 5 and Fig. 6), variation of sheer stress with speed gradient (Fig. 7 and Fig. 9) and flow curves (Fig. 8 and Fig. 10).

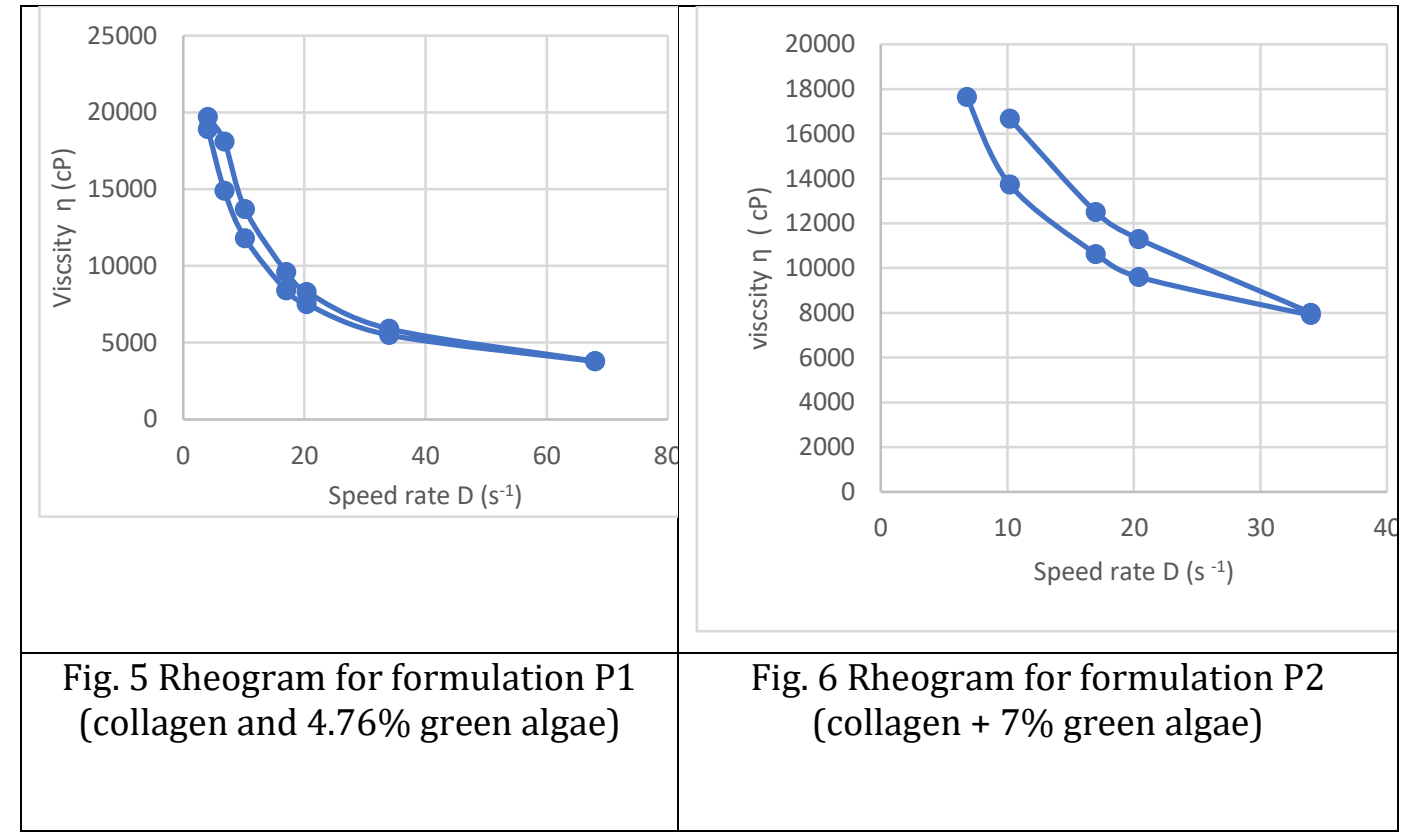

As it can be seen in figures 5 and 6, viscosity variation with speed gradient, the formulations have a pseudoplastic behaviour. Viscosity decreases as rotation speed increases. It can be noted that, at percentage of algae increases, the viscosity of the product increases. In figures 7 and 9, a more rapid increase of shear stress is noted at 
the same shear rates, with an increase in algae percentage. Hysterzis loops are wider for formulation P2, which has a higher percentage of green algae.

From analysing flow curves (figures 8 and 10), a linearization of curves for both formulations can be observed at increases of shear rates of over $20 \mathrm{sec}^{-1}$. This means they exhibit a tendency for ideal plastic behaviour at high shear rates, over $20 \mathrm{sec}^{-1}$, which practically means that the gel no longer changes its structure at shearing rates over the mentioned value.

\begin{tabular}{|c|c|c|c|}
\hline & & & \\
\hline
\end{tabular}

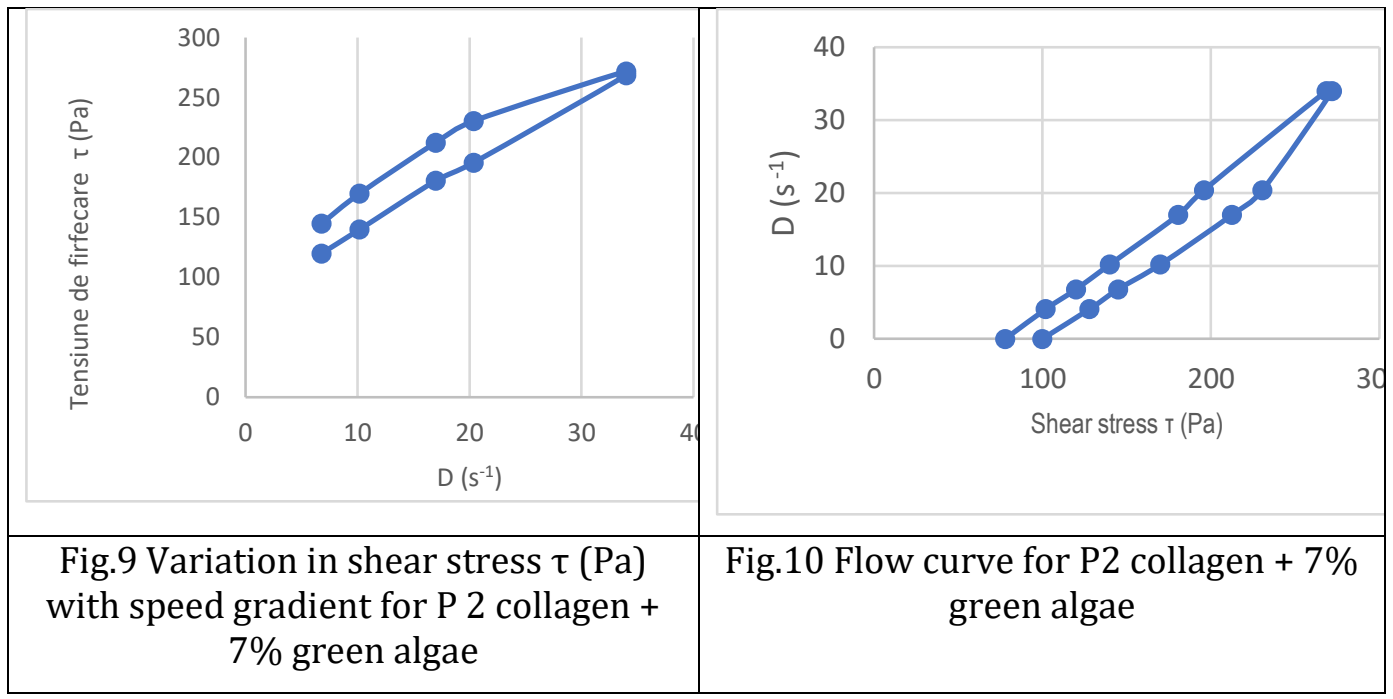

For a comparative study of the new pharmaceutical formulations and an appraisal of the interaction between algae and collagen components, which are represented by collagen gels containing marine algae powders from the Enteromorpha intestinalis 
and Cladophora vagabunda species, from the rheological data, the following were taken into account:

- Shear rate domains on which viscosity can be measured;

- Rheogram shape;

- Viscosity values at reduced sheer rates;

- Destructuration resistance (value of shear rate at which sudden destructuration is produced).

To the points mentioned above, the aspect of the gel - opalescent - was added - which can represent a proof of the compatibility of the components.

\section{Conclusions}

Formulations with different green algae content in collagen hydrolysate were obtained.

From the present study, the following conclusions can be drawn:

- Formulations with marine algae in the same type of collagen hydrolysate have a pseudoplastic rheological behaviour, with a decrease in apparent viscosity as shear rates increase.

- Formulations are stable and have an opalescent aspect.

- After the linearization of flow curves over a certain shear rate, formulations are stable and no longer modify structure.

- Based on the values of rheological parameters, it can be noted that formulation P2, with a higher percentage of algae in the same collagen hydrolysate, has a superior stability.

\section{References}

[1] Sîrbu R., Zaharia T., Negreanu-Pîrjol B.S, Nicolaev S., Bologa A.,Psegalinschi I, The Black Sea ecosystem - important potential source for pharmaceutical industry, Journal of Environmental Protection and Ecology, 11 (4): 13361348, ISSN 1311-5065, 2010,

[2] R. Sîrbu, T. Zaharia, V. Maximov, A.m. Bechir, M. Mariş, B. Negreanu-Pîrjol, D.Mariş, T. Negreanu-Pîrjol, M. Leca, E. M. Cadar, R. M. Stoicescu, L. Mocanu, S. Jurja, Clean bio-technologies for obtaining new pharmaceutical formulations based on collagen gels and marine algae extracts for medical applications, Journal of Environmental Protection and Ecology, 11 (2), 654665, 2010;

[3] R. Sirbu, T. Zaharia , A. M. Bechir, G. Lilios, S. Nicolaev , F. N. Roncea, Important Characteristics of the Marine Environment of the Romanian 
Littoral Coast -Favourable for Pharmaceutical Utilisat ions, Journal of Environmental Protection and Ecology, 13, No 3A, 1842-1855, 2012;

[4] R. Sirbu, T. Zaharia, A. Bechir, G. Lilios, S. Nicolaev, Characterisation of Marine Habitats Ecosystem and the Macro-algae Biodiversity along the Romanian Black Sea Shore Journal of Environmental Protection and Ecology, 13, No 1, 190-197, 2012;

[5] Rodica Sîrbu, Ticuta Negreanu-Pîrjol, Emin Cadar, Bogdan-Stefan NegreanuPîrjol, Active Principles which are Important to Human Health Obtained from Ceramium Rubrum - Seaweed in the Black Sea, Academic Journal of Interdisciplinary Studies, MCSER Publishing, Rome-Italy, Vol 4 No 1 S2, p. 253-258, April 2015;

[6] Ticuţa Negreanu-Pîrjol, B. Negreanu-Pîrjol, R. Sîrbu, G. Paraschiv, A. Meghea, "Comparative studies regarding the antioxidative activity of some therapeutic marine algae species along Romanian Black Sea Coast", Journal of Environmental Protection and Ecology (ISSN 1311-5065), vol.13, No. 3A, p. 1744-1750, 2012;

[7] Emin Cadar, Cristina-Luiza Erimia, Aneta Tomescu, Paris Stelian, Rodica Sîrbu, Marine Algae from Black Sea - Important Resources in the Pharmaceutical and Medical Research, European Journal of Interdisciplinary Studies (EJIS), Vol.4 , Nr. 1, p 24-30, 2016;

[8] Constanţa SAVA, Rodica SIRBU, "Analytical study of flavonoids determination in algae from the Black Sea, Ovidius University Annals of Chemistry, Volume 21, Number 1, pp29-34, 2010. 